\title{
Desigualdades Socioespaciais e seus Contrapontos Jurídicos: o caso do Plano Diretor Estratégico do Município de São Paulo
}

Les Inégalités Socio-spatiales et ses contrepoints juridiques: le cas du Plan

Directeur Stratégique de la Municipalité de São Paulo

Desigualdades Socioespaciales y sus Contrapuntos Jurídicos: el caso del Plan

Director Estratégico de São Paulo

Socio-Spatial Inequalities and their Legal Counterpoints: the case of the Strategic Master Plan of São Paulo

Jacques Felipe latchuk Vieira

\section{(2) OpenEdition}

\section{Journals}

\section{Edição electrónica}

URL: http://journals.openedition.org/espacoeconomia/7220

DOI: $10.4000 /$ espacoeconomia. 7220

ISSN: 2317-7837

\section{Editora}

Núcleo de Pesquisa Espaço \& Economia

Refêrencia eletrónica

Jacques Felipe latchuk Vieira, « Desigualdades Socioespaciais e seus Contrapontos Jurídicos: o caso do Plano Diretor Estratégico do Município de São Paulo », Espaço e Economia [Online], 15 | 2019, posto online no dia 28 outubro 2019, consultado o 05 novembro 2019. URL : http://journals.openedition.org/ espacoeconomia/7220; DOI : 10.4000/espacoeconomia.7220

Este documento foi criado de forma automática no dia 5 novembro 2019

(C) NUPEE 


\title{
Desigualdades Socioespaciais e seus Contrapontos Jurídicos: o caso do Plano Diretor Estratégico do Município de São Paulo
}

\author{
Les Inégalités Socio-spatiales et ses contrepoints juridiques: le cas du Plan \\ Directeur Stratégique de la Municipalité de São Paulo \\ Desigualdades Socioespaciales y sus Contrapuntos Jurídicos: el caso del Plan \\ Director Estratégico de São Paulo \\ Socio-Spatial Inequalities and their Legal Counterpoints: the case of the Strategic \\ Master Plan of São Paulo
}

Jacques Felipe latchuk Vieira

\section{Introdução'}

1 Com este trabalho, tem-se o objetivo de apresentar de forma breve o debate a respeito das desigualdades socioespaciais de caráter urbano dentro do contexto brasileiro, levando em conta a condição de país pertencente à periferia do capitalismo, e como tem-se tentado combater tais desigualdades por meio de instrumental jurídicourbanístico. Para isso, definiu-se por recorte territorial a cidade de São Paulo, tendo em vista sua inegável importância para os debates urbanos, bem como (como tentar-se-á demonstrar) devido à sua relação quase metonímica com as dinâmicas sociais do país.

Nesse sentido, o presente artigo está dividido em três itens, além das considerações finais. No primeiro item, são apresentadas as condições demográficas e econômicas que caracterizam o município de São Paulo e sua Região Metropolitana, de modo que fique clara a grandeza e importância desse território para as discussões a respeito do social e do urbano no Brasil. No segundo item, são focadas especificamente as desigualdades socioespaciais na cidade de São Paulo, e como elas são produto direto do modelo de 
sociedade que impera no país há séculos. Modelo esse que, resultado das características históricas do país, reflete em seus territórios as abissais desigualdades estruturais que lhe dão sustentação. No caso da capital paulista, isso faz com que seja possível falar em uma São Paulo das elites e uma São Paulo da classe trabalhadora. No terceiro item, são apresentados quatro instrumentos jurídico-urbanísticos constantes do Plano Diretor Estratégico do Município de São Paulo (Lei 16.050 de 31 de julho de 2014) que se erigem no intuito de transformar essa realidade de profundas desigualdades socioespaciais. Por fim, o trabalho é encerrado com algumas considerações finais a respeito dos avanços trazidos por essa legislação, mas também seus limites.

\section{São Paulo, coração econômico do Brasil}

3 São Paulo é a maior cidade de todo o sul global, sendo destaque nacional e internacional em questões como economia, turismo, cultura e diversidade. Ela abriga mais de 12 milhões de habitantes (IBGE, 2018a), sendo, com isso, a $7^{\mathrm{a}}$ cidade mais populosa de todo o mundo. Em média, são aproximadamente 8 mil habitantes por cada um dos seus 1.521 $\mathrm{km}^{2}$ (IBGE, 2018b), e a quase totalidade dessa população (99\%) reside em áreas urbanas. Para organizar politicamente esse território, a cidade é dividida em 31 prefeituras, que são subdivididas em 96 distritos.

4 Além disso, como consequência da própria formação brasileira, a população paulista tem origens muito diversas, com destaque para as migrações internas de grandes massas populacionais advindas de todas as regiões do país e dos milhões de imigrantes originários de variadas partes do mundo que vieram para a capital paulista. Consequentemente, São Paulo tem a interessante característica de possuir territórios intrinsecamente relacionados com culturas estrangeiras. Há bairros diretamente relacionados com as tradições italiana, portuguesa, espanhola, japonesa, libanesa, entre outras. Ainda, como maior cidade do continente, atraiu também grandes populações dos países vizinhos, com presença marcada de bolivianos, colombianos, peruanos etc. $\mathrm{E}$ também há, na estrutura paulistana, destaque especial (mesmo que seja algo insistentemente invisibilizado pelo Poder Público e pela grande mídia) para os territórios negros ${ }^{2}$, historicamente relacionados com a resistência da população negra à opressão estrutural da sociedade capitalista brasileira (ROLNIK, 2017).

5 A respeito da Região Metropolitana de São Paulo (RM-SP), a qual agrega 39 municípios com profundo processo de conurbação em uma única mancha urbana, ela tem mais de 21 milhões de habitantes, muito menos concentrados do que na capital, com uma média de 2,6 mil habitantes por cada um de seus quase $8 \mathrm{mil} \mathrm{km}^{2}$. Esses números a tornam a $5^{\mathrm{a}}$ maior aglomeração urbana do mundo (BREMAEKER, 2016). Para se ter uma ideia da dimensão que essa região metropolitana tem, em um comparativo nacional, os residentes na RM-SP são mais do que toda a população das regiões Norte ou CentroOeste, e ela é maior que o estado de Minas Gerais. Também, representa sozinha aproximadamente um quarto da região Sudeste e um décimo de toda a população brasileira. São grandezas próprias de um país.

6 Em relação à economia, o PIB do município de São Paulo ultrapassa os 650 bilhões de reais (IBGE, 2015) ${ }^{3}$, representativo de $10,85 \%$ do nacional. Fosse ele um estado, ocuparia o $3^{\circ}$ lugar no ranking do PIB nacional, atrás somente do restante do estado de São Paulo e, por diferença mínima, do Rio de Janeiro. Ademais, o PIB per capita no município é de $\mathrm{R} \$ 54.357,81$, sendo o terceiro maior dentre as capitais, atrás apenas de Vitória/ES e do 
Distrito Federal. A RM-SP, por sua vez, tem seu Produto Interno Bruto superior a 1 trilhão de reais, correspondente a aproximadamente 17,64\% do PIB brasileiro. Isso faz com que seja possível classificar a RM-SP como "o maior polo de riqueza nacional" (IPEA, 2013).

7 Esse aglomerado que se formou tendo por centro de referência a cidade de São Paulo tem a maior concentração populacional do país, é centro de decisões políticas e de oferta de serviços, polo de turismo e abrigo de sedes de empresas transnacionais, além de ter um complexo industrial e importante centro financeiro ${ }^{4}$. Todas essas características tornam a RM-SP absolutamente central para as discussões a respeito dos rumos da economia nacional. E também fazem com que essa região seja de enorme interesse das elites que têm por objetivo apenas a acumulação.

8 Nesse sentido, a respeito do papel de São Paulo no âmbito econômico brasileiro, podemos afirmar que ela:

é o coração econômico do Brasil e assim tanto seu desenvolvimento em geral como as características específicas de seu desenvolvimento estão entrelaçadas com o desenvolvimento econômico e social do Brasil como um todo. [...] sua magnitude e dinamismo, mas também sua fraqueza estrutural, são a um só tempo, uma consequência e um meio de reprodução, são uma parte orgânica, do desenvolvimento do país. (DÉAK; SCHIFFER, 2007, p. 2)

9 Consolida-se, consequentemente, uma relação metonímica de São Paulo com o Brasil, sendo essa cidade uma representação das características sociais que compõem o país, com destacada acentuação das contradições de classe, raça e gênero que permeiam o desenvolvimento brasileiro. São Paulo é onde a realidade brasileira de colossais desigualdades é mais palpável. Como tentaremos demonstrar, existe uma São Paulo da elite e uma São Paulo da classe trabalhadora, com realidades sociais, culturais, políticas e estruturais absolutamente diferentes. E, mais do que isso, têm entre si uma relação de dualidade, em que não se pode analisar essas diferenças apenas como elementos de moderno e de arcaico independentes (ARANTES, 1992). Na verdade, um é produto e produtor do outro, em uma constante relação dialética.

10 A origem disso está relacionada com o fato de que:

A sociedade brasileira é profundamente diferente das sociedades dos países centrais do capitalismo mundial. [...] Florestan Fernandes a chamou de sociedade de elite, como distinta de burguesa, como uma super-privilegiada classe dominante. Já a base material dessa sociedade é a reprodução de uma peculiar modalidade de acumulação, ou desenvolvimento, que tem origem no status colonial do Brasil anterior a Independência (1822) e reproduzido desde então. Nesse processo, o excedente produzido pela sociedade é dividido em duas partes, uma das quais é reinvestida na expansão da produção (e nesse sentido, é reprodução ampliada, um processo de acumulação), enquanto a outra parte é constantemente drenada e enviada para o exterior -expatriada- sob a forma de pagamento de juros, remessa de lucros, termos desfavoráveis de comércio e crônico déficit em serviços (pagamento de fretes e seguros no comércio exterior) sem qualquer tipo de contrapartida, de forma que muito pouco é acumulado. É acumulação, então, mas não de todo o excedente produzido, daí a denominação de acumulação entravada. As características distintivas de tal economia: taxas de juros astronômicas; inexistência de crédito de longo prazo ou moeda estável; desnacionalização da produção, especialmente em áreas-chave da indústria e infra-estrutura precária, seriam vistos em uma sociedade capitalista burguesa (tal como as existentes em países 'desenvolvidos'), como fraquezas estruturais da economia, quando na verdade são, no Brasil, os principais instrumentos da contínua reprodução do status quo. [...] A sociedade de elite desenvolve suas formas políticas particulares também. Assim, se 
a democracia é a forma política própria da sociedade burguesa, construída sobre a idéia de bem-comum (Commonwealth) e da concreta igualdade dos cidadãos perante a lei, na sociedade de elite ela se torna uma farsa porque o superprivilegiamento da elite contradiz qualquer noção de bem-comum, e a igualdade perante a lei simplesmente não existe. [...] A elite faz (uma quantidade ilimitada de inconseqüentemente ambiciosas e ridiculamente detalhadas) leis somente para desrespeitá-las, e assim reafirmam sua autoridade em ambos os movimentos: ela pode fazer a lei e ela pode infringi-la no momento seguinte; e essa dinâmica é socialmente aceita como normal. (DÉAK; SCHIFFER, 2007, p. 8-9)

11 Esse desenvolvimento característico da sociedade brasileira enquanto sociedade de elite acabou por também influenciar na formação dos espaços urbanos. Isso quer dizer que as cidades brasileiras também são produzidas de modo a privilegiar as elites nacionais, independentemente das consequências políticas, econômicas e sociais que isso possa ter. Assim, São Paulo, como local mais intenso dessas contradições, é uma cidade essencialmente desigual, com realidades diametralmente opostas vividas, a mínima distância, por uma elite numericamente mínima e uma esmagadora maioria de membros da classe trabalhadora. No país onde seis pessoas controlam a mesma riqueza que os 100 milhões de habitantes mais pobres, e os $5 \%$ mais ricos recebem, por mês, o mesmo que os demais 95\% juntos (OXFAM, 2017), a metrópole paulista - "coração econômico" do país - materializa essas distorções e desigualdades na constituição do seu espaço. Não por outro motivo, seguindo a lógica de concentração de renda que rege o país, em São Paulo 1\% dos proprietários de imóveis concentra o equivalente a $45 \%$ do valor imobiliário municipal ${ }^{5}$.

\section{Desigualdade e Produção do Espaço em São Paulo}

12 Como dito, podemos entender a capital paulista como duas cidades diferentes. De um lado, a cidade formal; de outro, a cidade ilegal.

13 A cidade formal é onde residem as populações com rendas mais elevadas que a média da população e são aplicadas e protegidas as normas e leis urbanísticas (desde que não atrapalhem o processo de valorização do valor). Também, há certa infraestrutura de qualidade e oferta de serviços e equipamentos públicos bem mantidos, além de constante preocupação do Poder Público com a manutenção dos níveis de qualidade das áreas públicas, do paisagismo, da pavimentação e da iluminação. A cidade formal é o espaço onde o Estado se mostra efetivamente presente, seja por meio de grandes investimentos pelo Executivo e pelo Legislativo, seja por meio da garantia da lei pelo Judiciário (MARICATO, 2000). Essa parcela do território urbano paulistano é onde os planos urbanísticos feitos ao longo da história da cidade têm validade. Tal constatação serve para reforçar o fato de que a legislação urbanística não é apenas mero instrumental puramente técnico, sem interesses políticos e econômicos, deslocado das demais questões da sociedade (ROLNIK, 1997).

o Direito, inclusive quando regula a cidade, é afetado pelos interesses em disputa e pelas condições da luta de classes. Na questão urbana, o Estado e as forças dominantes do capital monopolista unem-se no conflito social contra as classes populares (OLIVEIRA, 1982). O que está por trás dessa disputa é se vai prevalecer o entendimento da terra como valor de troca ou como valor de uso (MARICATO, 2015). E a tradição da sociedade de elite no Brasil mostra que a legislação é um instrumento de dupla reafirmação do seu poder sobre a classe trabalhadora: por um lado, é ela (a elite) quem 
elabora e aplica as leis, determinando o que é ou não aceito, o que será ou não alvo do poder de violência do Estado; por outro, essa elite reiteradamente desrespeita o conteúdo das leis que ela mesma elaborou, quando assim lhe convém, sem quaisquer cerimônias, justamente porque essas infrações servirão para a conquista de objetivos particulares. Há uma total displicência com relação a princípios basilares de uma democracia capitalista clássica, como a igualdade perante a lei ou a noção de interesse público ${ }^{6}$.

Quando aplicada à produção do espaço urbano, essa "tradição brasileira gera, para essas elites, territórios absolutamente deslocados da realidade da maior parte da população. Nesse sentido, a elite apropriou-se de territórios da cidade de São Paulo e produziu-os de acordo com seus interesses e conviç̧ões. A expressão mais forte e evidente disso concretiza-se no quadrante sudoeste de São Paulo (VILLAÇA, 2011). Essa parcela do município paulistano foi se reproduzindo ao longo da história de modo a mimetizar o que seriam os grandes centros urbanos de países centrais, ignorando completamente as desigualdades concretas tão profundamente enraizadas na sociedade brasileira (FIX, 2012). Seu skyline, que segue o modelo das cidades que tentam se projetar ao mundo como grandes atores políticos (BORJA \& CASTELLS, 1996), consolida-se como a demonstração semiótica de maior poder sobre todos aqueles que estão ao seu redor (e, física e socialmente, abaixo) (PIGNATARI, 2004).

16 Área de assentamento da elite paulistana e de grande investimento do mercado financeiro e imobiliário, esse território concentra em si a maior parte dos recursos públicos e privados (FIX, 2012), apresenta melhores condições de infraestrutura do que o restante da cidade de São Paulo (DÉAK; SCHIFFER, 2017) e possui índices sociais muito elevados (REDE NOSSA SÃO PAULO, 2017). Ao mesmo passo, os distritos desse quadrante concentram as mais altas rendas médias familiares, os maiores IDHs da capital paulista e os menores números de óbitos por homicídio por 100 mil (VILLAÇA, 2011). Também é nessa região que, hoje, não por coincidência, localiza-se o complexo corporativo de São Paulo (ALVES, 2018).

17 Em contrapartida, há a cidade ilegal. Habitada pelas camadas mais pobres da classe trabalhadora e abrigando a parte majoritária dos pretos e pardos residentes no município, uma de suas características principais é a presença de alguma forma de irregularidade na relação de seus habitantes com a terra. Enquadram-se nessa situação as ocupações ilegais de terras pela população pobre para autoconstrução de moradias (ou seja, as favelas), mas também locais onde há contratos de compra e venda. Estruturam-se, porém, em um loteamento ilegal, onde há níveis variados de irregularidades (MARICATO, 2007).

18 Essa cidade ilegal cresceu e teve seus focos multiplicados ao longo da história das cidades brasileiras, em especial de São Paulo, por ser a única alternativa à enorme parcela da população que acaba ficando excluída da participação no mercado imobiliário formal, restringindo-se a essa alternativa ou à pequena atenção dada a ela por meio de políticas públicas de moradia. Principalmente frente ao brutal avanço da especulação imobiliária, que assola a cidade de São Paulo ${ }^{7}$. Durante a década de 90 , as estimativas de moradias em alguma forma de ilegalidade chegavam a $70 \%$ do total de imóveis na cidade (MARICATO, 1996). Depois de seguidos processos de anistia, esse número tem se reduzido (PASTERNAK, 2010), mas a realidade atual não deixa de ser assustadora. Hoje, os dados (quando incluem também os cortiços e ocupações de prédios abandonados no centro de São Paulo) indicam algo próximo de $30 \%$. As favelas 
dão abrigo a 1.307.152 habitantes, já os loteamentos irregulares têm um total de 1.739.473 residentes (CEM, 2016). São, assim, ao menos 3 milhões de pessoas residindo em imóveis atingidos por algum tipo de irregularidade.

19 Para além disso, é notável como a produção capitalista do espaço urbano, principalmente na periferia do capitalismo, em uma sociedade de elite como a brasileira, torna possível a visualização geográfica das abissais desigualdades sociais. Nesse sentido, a cidade de São Paulo, em sua forma, deixa claras características que a fundamentam, como a enorme desigualdade de renda e o racismo de uma sociedade que ainda não soube tratar de maneira adequada seu passado escravocrata. O Mapa da Desigualdade, produzido anualmente pela Rede Nossa São Paulo (2017), dá números claros, por distrito, a essas discrepâncias. Podemos citar, por exemplo:

- Na Vila Andrade (Zona Sul), 50,45\% das moradias ficam localizadas em favelas. Em 11 distritos (todos no Quadrante Sudoeste ou na Zona Central), não há favelas.

- A remuneração média do emprego formal em dezembro de 2015 em Marsilac (extremo sul de São Paulo) era de R\$1.287,32. No Campo Belo (que faz parte do Quadrante Sudoeste), $\mathrm{R} \$ 10.079,98$.

- A idade média ao morrer entre os residentes do Jardim Paulista (também no Quadrante Sudoeste) é de 79,4 anos. No Jardim Ângela (que fica na Zona Sul e é o terceiro maior distrito em população do município), 55,7 anos, algo comparável a países da África Subsaariana. Isso quer dizer que, a depender do local de residência, as pessoas podem viver até mais do que a média dos EUA ou igual aos moradores da Somália (OMS, 2016). A diferença na expectativa de vida entre esses distritos é de assustadores 23,7 anos.

- Dos 10 distritos com mais homicídios por 100 mil habitantes em São Paulo no ano de 2015, 4 ficam na Zona Leste, 3 na Zona Sul, 2 na Zona Central e 1 na Zona Norte. Dos 10 com menos homicídios, 7 ficam no Quadrante Sudoeste.

Nesse sentido, vale recorrer novamente às palavras de Ermínia Maricato, que diz:

A tensão existente entre a cidade formal e a cidade ilegal é dissimulada. [...] a representação da 'cidade' é uma ardilosa construção ideológica que torna a condição de cidadania um privilégio e não um direito universal: parte da cidade torna o lugar do todo. A cidade da elite representa e encobre a cidade real. Essa representação, entretanto, não tem a função apenas de encobrir privilégios, mas possui, principalmente, um papel econômico ligado à geração e captação de renda imobiliária. (MARICATO, 2000, p. 165)

21 Com uma realidade de disparidades socioespaciais tão gritantes, a democratização do espaço urbano e a construção do Direito à Cidade em São Paulo passam diretamente por duas frentes de atuação: a garantia de participação popular na tomada de decisões a respeito dos rumos da cidade e a redução drástica das desigualdades materiais na cidade.

\section{O Plano Diretor de São Paulo frente às Desigualdades Socioespaciais}

Como demonstrado, a cidade de São Paulo é assolada por gigantescas desigualdades. Essas desigualdades têm ligação com a própria forma da sociedade brasileira, uma sociedade elitista do capitalismo periférico. Isso, por sua vez, reflete diretamente na produção de nossos espaços urbanos, fazendo com que as cidades brasileiras sejam estruturadas para servir aos interesses da elite nacional, sem dar importância para os 
efeitos que isso possa causar à classe trabalhadora. Assim, nossas profundas desigualdades sociais acabam por ter também um caráter espacial, o que faz com que seja possível visualizarmos de forma territorializada as discrepâncias nas condições de vida da população. Nas cidades brasileiras, riqueza e pobreza têm lugares definidos. suas casas, mas principalmente às realidades que têm de enfrentar no espaço público para participar da dinâmica social.

As cidades são o principal local onde se dá a reprodução da força de trabalho. Nem toda melhoria das condições de vida é acessível com melhores salários ou com melhor distribuição de renda. Boas condições de vida dependem, frequentemente, de políticas públicas urbanas - transporte, moradia, saneamento, educação, saúde, lazer, iluminação pública, coleta de lixo, segurança. Ou seja, a cidade não fornece apenas o lugar, o suporte ou o chão para essa reprodução social. Suas características e até mesmo a forma como se realizam fazem a diferença. (MARICATO, 2013, p. 19-20)

É por esse motivo que, apesar de as condições materiais privadas da população terem, em geral, melhorado durante o início do século XXI (com grande oferta de empregos associada a uma política de aumento real do salário mínimo, além dos programas assistencialistas garantidos pelo Estado), ainda assim a vida da classe trabalhadora nos territórios urbanos continuou piorando, já que as cidades se mantiveram seguindo a lógica da exclusão e limitando o direito à cidade a uma parcela muito pequena da população ${ }^{8}$.

Uma expressão repetida incessantemente no país [...] oferece uma versão simplificada do paradoxo diminuição da pobreza/crescimento econômico e agudização da crise urbana: da porta para dentro avançamos (leia-se: compramos geladeiras, computadores, celulares, viagens de férias etc.), da porta para fora estamos cada vez pior (leia-se: a dimensão pública, coletiva, das políticas, a infraestrutura social e econômica inexistente, insuficiente ou precária). (ROLNIK, 2015, p. 271)

Por conseguinte, para que possamos enfrentar as desigualdades sociais historicamente construídas no Brasil, é necessário que as encaremos como desigualdades socioespaciais. Para tanto, a gestão democrática da cidade (repetidamente enfatizada e prevista tanto pelo Estatuto da Cidade 9 quanto pelo próprio Plano Diretor Estratégico de São Paulo ${ }^{10}$ ) é elemento fundamental, visto que garante espaço para a participação popular no centro das instâncias de tomada de decisão a respeito dos rumos da política urbana. No entanto, mais do que isso, é necessário que a participação popular gere uma inversão de prioridades na atuação urbanística do Estado, de modo a democratizar materialmente os espaços urbanos, melhorando a qualidade de vida, a infraestrutura e os serviços oferecidos nas localidades mais precárias, além de criar habitação onde as condições ofertadas já são boas. Em São Paulo, isso passa por, entre outras coisas, investir mais na cidade ilegal (especialmente nas zonas Sul e Leste, que abrigam a maior parte dos habitantes paulistanos) e criar moradias populares no centro e no Quadrante Sudoeste.

São Paulo é extremamente desigual. Os investimentos, as oportunidades de emprego e a oferta de bens e serviços urbanos são concentrados em uma pequena parcela central do território, enquanto a vulnerabilidade predomina nas áreas periféricas. A taxa de crescimento populacional se estabiliza, porém o déficit por moradias ainda é da ordem de centenas de milhares e gera pressão pela urbanização extensiva sobre áreas ambientalmente sensíveis do município. São Paulo só pode se desenvolver e se transformar por dentro. A questão é, portanto, como reequilibrar 
as dinâmicas urbanas, acolhendo a todos dignamente e aproximando as oportunidades de emprego e moradia por toda a cidade. (PREFEITURA DE SÃO PAULO, 2015, p. 7)

Frente a isso, o Plano Diretor estabelece algumas regras e instrumentos importantes. Tratemos aqui de quatro pontos específicos trazidos pela lei 16.050/14 sobre esse tema: a) o Fundo Municipal de Desenvolvimento Urbano (FUNDURB); b) a Cota de Solidariedade; c) as Zonas Especiais de Interesse Social (ZEIS); e d) os instrumentos indutores da Função Social da Propriedade.

\section{a) o Fundo Municipal de Desenvolvimento Urbano (FUNDURB)}

O FUNDURB é um importante instrumento para a transformação da cidade. Sua principal fonte de receitas é a Outorga Onerosa (art. 337), e é importante que a expliquemos para que seja possível entender o papel do Fundo na construção de uma cidade mais democrática.

A Lei 16.050 faz com que em todo o espaço urbano de São Paulo tenha Coeficiente Aproveitamento Básico igual a $1^{11}$, isto é, garante ao proprietário o direito de construir o equivalente a uma vez a área do lote. Caso seja de interesse do empreendedor construir além desse valor, até o limite máximo estabelecido, ele terá de pagar à Prefeitura a Outorga Onerosa do Direito de Construir, isto é, uma contrapartida financeira pelo potencial construtivo adicional, que tem seu valor calculado de acordo com as regras as regras do art. 117. E esses recursos recebidos por meio da Outorga Onerosa são destinados exclusivamente ao FUNDURB (art. 115, Parágrafo único).

É notável o papel que essa regra tem para a democratização material da cidade quando vemos como o FUNDURB investe seus recursos. Determina a lei:

Art. 339. Os recursos do Fundo de Desenvolvimento Urbano - FUNDURB serão aplicados com base nos objetivos, diretrizes, planos, programas e projetos urbanísticos e ambientais integrantes ou decorrentes da Lei do Plano Diretor Estratégico e tendo como referência o previsto no Programa de Metas do Município, conforme as seguintes prioridades:

I - execução de programas e projetos habitacionais de interesse social, incluindo a regularização fundiária e a aquisição de imóveis para constituição de reserva fundiária e de parque habitacional público de locação social;

II - sistema de transporte coletivo público, sistema cicloviário e sistema de circulação de pedestres;

III - ordenamento e direcionamento da estruturação urbana, incluindo infraestrutura, drenagem, saneamento, investimentos destinados à implantação de parques lineares, à realização de melhorias em vias estruturais ou de transporte público coletivo de passageiros e à requalificação de eixos ou polos de centralidade; IV - implantação de equipamentos urbanos e comunitários, espaços públicos de lazer e áreas verdes;

V - proteção, recuperação e valorização de bens e de áreas de valor histórico, cultural ou paisagístico, incluindo o financiamento de obras em imóveis públicos classificados como ZEPEC;

VI - criação de unidades de conservação ou proteção de outras áreas de interesse ambiental.

Além disso, deixa clara e obrigatória a prioridade dada à questão da moradia popular (especialmente na região central da cidade, que já possui estrutura e serviços de qualidade, além de alta oferta de empregos) e ao transporte público: 
Art. 340. Os recursos arrecadados pelo FUNDURB deverão respeitar anualmente o limite de:

I - ao menos $30 \%$ (trinta por cento) destinados para a aquisição de terrenos destinados à produção de Habitação de Interesse Social localizados na Macroárea de Estruturação Metropolitana, e na Macroárea de Urbanização Consolidada e na Macroárea de Qualificação da Urbanização, preferencialmente classificados como ZEIS 3, conforme Mapa $4^{\mathrm{a}}$ anexo;

II - ao menos $30 \%$ (trinta por cento) destinados à implantação dos sistemas de transporte público coletivo, cicloviário e de circulação de pedestres.

31 Com essa vinculação dos recursos do Fundo, a legislação deixa claro o entendimento de que a autorização para que o empreendedor construa acima do Coeficiente de Aproveitamento Básico só pode ser dada por meio de uma contrapartida que, mais do que meramente financeira, venha no sentido de beneficiar a coletividade da cidade, com especial foco àqueles que estão em situação mais vulnerável. Ou seja, há aqui uma tentativa de inversão da relação que o Poder Público de São Paulo tem tido historicamente com o mercado imobiliário: se antes os elementos de interesse da coletividade eram submetidos a um segundo plano para que se desse privilégios aos interesses do mercado imobiliário, agora este só poderá concretizar seus projetos (os quais trazem claros efeitos sobre a estrutura e o cotidiano do espaço urbano) se isso vier acompanhado de pagamento para que se invista na melhoria de vida da maior parte da população.

Isso, somado ao fato de que o FUNDURB é submetido a uma gestão democrática com controle social garantido por meio do Conselho Gestor paritário (art. 341), torna-o instrumento central para reduzir as desigualdades socioespaciais, com um espaço mais democrático e capaz de ser experienciado por parcelas cada vez maiores dos moradores.

\section{b) a Cota de Solidariedade}

33 A Cota de Solidariedade é um mecanismo regulamentado pelos arts. 111 e 112 do PDESP que obriga os empreendimentos imobiliários maiores que $20.000 \mathrm{~m}^{2}$ a determinarem o equivalente a $10 \%$ da área construída computável para Habitação de Interesse Social, a qual é destinada a famílias com renda de até seis salários mínimos. Com esse instrumento, há uma ampliação do acesso à terra para produção de moradia popular. No entanto, o lobby do mercado imobiliário na Câmara Municipal fez com que, durante a tramitação no Legislativo, a Cota de Solidariedade tenha sido profundamente enfraquecida, já que a ideia inicial presente no Projeto de Lei 688/13 era que a construção das HIS referentes à cota fosse no próprio terreno ou em terreno próximo, o que serviria para garantir que haveria produção de moradia social em áreas já estruturadas e valorizadas. Colocaria gente pobre para morar onde hoje vivem quase que exclusivamente só ricos. Com as alterações, foi aberta a possibilidade de os empreendedores cumprirem os requisitos da Cota de Solidariedade de maneiras alternativas (art. 112, \$2º), o que, em suma, deixa que paguem para que as habitações sejam construídas longe de seus empreendimentos. É um atentado contra a função inicial do instrumento. 


\section{c) as Zonas Especiais Interesse Social (ZEIS)}

34 O Plano Diretor também trata sobre as Zonas Especiais de Interesse Social (ZEIS) que, apesar de já existirem desde o PDE-SP de 2002 e serem regulamentadas por lei própria (Lei 13.885/04), tiveram suas áreas de cobertura expandidas de $138,8 \mathrm{~km}^{2}$ para $172 \mathrm{~km}^{2}$ (um aumento de quase 25\%) e foram aperfeiçoadas. Por serem um instrumento central para a transformação do modelo de cidade, elas são citadas em diversos artigos, mas o trecho da lei referente especificamente à regulamentação das ZEIS está contido entre os arts. 44 e 60. A definição delas está no art. 44:

Art. 44. As Zonas Especiais de Interesse Social (ZEIS) [...] são porções do território destinadas, predominantemente, à moradia digna para a população de baixa renda por intermédio de melhorias urbanísticas, recuperação ambiental e regularização fundiária de assentamentos precários e irregulares, bem como à provisão de novas Habitações de Interesse Social - HIS e Habitações de Mercado Popular - HMP a serem dotadas de equipamentos sociais, infraestruturas, áreas verdes e comércios e serviços locais, situadas na zona urbana.

Ou seja, através das ZEIS a lei demonstra uma clara intenção de enfrentar a questão da cidade ilegal. Isso é reiterado quando vemos a área de cobertura das ZEIS, que em geral coincide com onde as condições de vida são mais precárias, como já apontado. Ademais, sabendo da necessidade de tratar as especificidades de cada área, o Plano Diretor estabelece distintos tipos de ZEIS para o tratamento diferenciado das problemáticas de cada região:

Art. 45. As ZEIS classificam-se em 5 (cinco) categorias, definidas nos seguintes termos:

I - ZEIS 1 são áreas caracterizadas pela presença de favelas, loteamentos irregulares

e empreendimentos habitacionais de interesse social, e assentamentos habitacionais populares, habitados predominantemente por população de baixa renda, onde haja interesse público em manter a população moradora e promover a regularização fundiária e urbanística, recuperação ambiental e produção de Habitação de Interesse Social;

II - ZEIS 2 são áreas caracterizadas por glebas ou lotes não edificados ou subutilizados, adequados à urbanização e onde haja interesse público ou privado em produzir Empreendimentos de Habitação de Interesse Social;

III - ZEIS 3 são áreas com ocorrência de imóveis ociosos, subutilizados, não utilizados, encortiçados ou deteriorados localizados em regiões dotadas de serviços, equipamentos e infraestruturas urbanas, boa oferta de empregos, onde haja interesse público ou privado em promover Empreendimentos de Habitação de Interesse Social;

IV - ZEIS 4 são áreas caracterizadas por glebas ou lotes não edificados e adequados à urbanização e edificação situadas na Área de Proteção aos Mananciais das bacias hidrográficas dos reservatórios de Guarapiranga e Billings, exclusivamente nas Macroáreas de Redução da Vulnerabilidade e Recuperação Ambiental e de Controle e Recuperação Urbana e Ambiental, destinadas à promoção de Habitação de Interesse Social para o atendimento de famílias residentes em assentamentos localizados na referida Área de Proteção aos Mananciais, preferencialmente em função de reassentamento resultante de plano de urbanização ou da desocupação de áreas de risco e de preservação permanente, com atendimento à legislação estadual;

V - ZEIS 5 são lotes ou conjunto de lotes, preferencialmente vazios ou subutilizados, situados em áreas dotadas de serviços, equipamentos e infraestruturas urbanas, onde haja interesse privado em produzir empreendimentos habitacionais de mercado popular e de interesse social. 
O Plano também prevê que o planejamento e a execução das intervenções realizadas nas ZEIS 1 e 3 devem ter a participação de um Conselho Gestor composto por representantes dos moradores, do Poder Executivo e da sociedade civil organizada, impedindo uma intervenção estatal sem qualquer participação das pessoas que serão afetadas. Ainda, determina que ao menos $60 \%$ da área construída de HIS em ZEIS 1, 2, 3 e 4 seja destinada às famílias com renda de até 3 salários mínimos. Também, utiliza esse instrumento para estimular a proximidade entre o local de domicílio e de empregos, abrindo a possibilidade para, nas ZEIS, serem considerados não computáveis até $20 \%$ da área construída dos EHIS e dos EHMP destinada à oferta de serviços, comércio e equipamentos (art. 60, $4^{\circ}$ ).

\section{d) os instrumentos indutores da Função Social da Propriedade ${ }^{12}$}

A aplicação da Função Social da Propriedade passa diretamente pelo combate à utilização de imóveis para especulação imobiliária. Nesse sentido, o Plano pretende enfrentar os imóveis que não são utilizados de acordo com as necessidades coletivas, ou seja, aqueles não edificados, aqueles subutilizados e aqueles não utilizados. Para isso, se vale dos instrumentos ofertados pelo Estatuto da Cidade, como o Parcelamento, Edificação ou Utilização Compulsórios (PEUC), o IPTU Progressivo no Tempo e a Desapropriação Mediante Pagamento em Títulos de Dívida Pública. De acordo com os arts. 96 e 97, nos casos dos imóveis não edificados ou subutilizados, os proprietários devem, compulsoriamente, no prazo de um ano apresentar projeto de parcelamento ou edificação, iniciar as obras em até dois anos da data do alvará de execução do projeto e concluí-las em até 5 anos. Já os proprietários de imóveis não utilizados têm um ano para dar-lhes uso. Não sendo cumpridos esses prazos ou as obrigações postas, a Prefeitura deve cobrar dos proprietários IPTU Progressivo no Tempo (art. 98), que tem sua alíquota aumentada a cada ano, até o máximo de $15 \%$, para forçar o proprietário a dar função social a seu imóvel. Caso ele siga não cumprindo o que a lei manda, após 5 anos de aumento do IPTU, a Prefeitura pode realizar a Desapropriação Mediante Pagamento em Títulos da Dívida Pública (art. 99). o Plano também prevê a listagem dos imóveis que não cumprem função social (que será disponibilizada ao público para garantir o monitoramento e o controle social do combate à especulação imobiliária), no arts. 100 e 101; o Consórcio Imobiliário entre Prefeitura e proprietário para viabilizar financeiramente a garantia da função social dos imóveis, conforme o art. 102; o Direito de Preempção à Prefeitura para aquisição de imóvel urbano objeto de alienação onerosa entre particulares, para que seja possível cumprir os objetivos e as ações prioritárias do PDE, como mostram os arts. 103 a 107; e a Arrecadação de Bens Abandonados, onde a Prefeitura terá o direito de incorporar ao patrimônio do Município os imóveis que não cumprirem suas obrigações fiscais e de conservação por um prazo de três anos, como determinado pelos arts. 108 a 110 .

\section{Considerações Finais}

38 Todos esses diversos instrumentos aqui apresentados (o FUNDURB, a Cota de Solidariedade, as ZEIS e os mecanismos indutores de Função Social da Propriedade), bem como outros ${ }^{13}$, vão no sentido de reduzir as desigualdades socioespaciais existentes em São Paulo e aproximar cada vez mais as realidades experienciadas na cidade por 
aqueles que pertencem a diferentes segmentos sociais. Apenas com a transformação da cidade em um lugar que seja mais igual, materialmente democrático, e que permita aos seus habitantes oportunidades de vivências comuns é possível caminhar em direção ao Direito à Cidade. Porque o Direito à Cidade também se refere ao direito de experiência de unidade ${ }^{14}$, o que é inconcebível em um espaço marcado por desigualdades socioespaciais tão profundas quanto as presentes em São Paulo.

No entanto, apesar dos inegáveis avanços trazidos pelo PDE-SP e seu instrumental jurídico-urbanístico, cabe destacar que não é possível iludir-se por uma lei que se apresenta de forma mais socialmente progressista, especialmente quando se trata de assunto tão central para a luta de classes quanto a produção do espaço urbano. Afinal, a história brasileira é marcada por profundo e tradicional distanciamento entre a realidade social e o arcabouço jurídico (MARICATO, 2000), o que, em diversos momentos, acabou por frustrar muitos dos que lutavam por transformações na produção do espaço urbano brasileiro.

Como nos lembra Flávio Villaça (2005), não podemos cair na "ilusão do Plano Diretor" ${ }^{15}$, visto que a aplicação do que está escrito na lei não é algo completamente garantido. 0 Plano Diretor Estratégico anterior (Lei $\mathrm{n}^{\circ} 13.430$, de 13 de setembro de 2002), por exemplo, tinha princípios (art. $7^{\circ}$ ) e objetivos (art. $8^{\circ}$ ) ainda mais abrangentes do que o atual, ambicionando de forma expressa pontos como a justiça social, o direito universal à moradia digna e a universalização da mobilidade e acessibilidade (com prioridade ao transporte público coletivo), bem como a participação da população nos processos de decisão, planejamento e gestão. A despeito da presença desses princípios na lei fulcral de todo o desenvolvimento da capital paulista, São Paulo manteve-se no caminho de aprofundamento das desigualdades socioespaciais, com uma enorme parcela da população vivendo sob condições de precariedade e ilegalidade, submetidas a uma realidade de imobilidade e serviços precários, enquanto as áreas de interesse do mercado imobiliário e das elites dominantes (que, essas sim, sempre tiveram garantida sua participação na tomada de decisão do Poder Público) continuaram se desenvolvendo a passos largos, descoladas da realidade vivida pelo restante da cidade.

Por isso, mais do que apenas a elaboração de leis e instrumentos jurídico-urbanísticos, uma nova cidade só será possível por meio da participação popular e da luta cotidiana em defesa da democratização do espaço, do embate entre os interesses das classes populares e os das elites. Afinal, como afirma Francisco de Oliveira (apud. VAINER, 2000, p. 117), "o planejamento é uma forma transformada da luta de classes".

\section{BIBLIOGRAFIA}

ALVES, C. Z. J. A formação do complexo corporativo metropolitano de São Paulo baseado na distribuição das sedes dos bancos de investimento (1966-2013). In: Geousp - Espaço e Tempo (Online), v. 22, n. 1, p. 096-114. 2018. 
ARANTES, Paulo Eduardo. Sentimento da Dialética na Experiência Intelectual Brasileira: Dialética e Dualidade segundo Antonio Candido e Roberto Schwarz. Rio de Janeiro: Paz e Terra, 1992.

BORJA, Jordi; CASTELLS, Manuel. As Cidades como Atores Políticos. In: Novos Estudos Cebrap, n. 45, p. 152-166. São Paulo: Cebrap, 1996.

BRASIL. Lei no 10.257 , de 10 de julho de 2001. Regulamenta os arts. 182 e 183 da Constituição Federal, estabelece diretrizes gerais da política urbana e dá outras providências. Disponível em: <http://www.planalto.gov.br/ccivil_03/Leis/LEIS_2001/L10257.htm>. Acessado em 04 de maio de 2019.

BREMAEKER, François. As Grandes Aglomerações Urbanas no Mundo. Rio de Janeiro: Observatório de Informações Municipais, 2016.

Centro De Estudos Da Metrópole (CEM). Estimativas Relativas à Precariedade Habitacional e ao Déficit Habitacional no Município de São Paulo - Sehab/PMSP e CEM/CEPID. São Paulo: CEM, 2016.

DÉAK, Csaba; SCHIFFER, Sueli. A Metrópole de uma Sociedade de Elite. In: SEGBERS, Klaus (et al.). The making of global city-regions. Baltimore: The John Hopkins University Press, 2007. Tradução de Nuno Fonseca. Disponível em: <http://www.fau.usp.br/docentes/depprojeto/c_deak/CD/ 3publ/07sp-metr-elit/07-SP-Met-po.pdf>. Acessado em 04 de maio de 2019.

FIX, Mariana. Parceiros da Exclusão: duas histórias de construção de uma "nova cidade" em São Paulo. São Paulo: Boitempo Editorial, 2012.

Instituto Brasileiro de Geografia e Estatística (IBGE). Área territorial brasileira. Rio de Janeiro: IBGE, 2018b.

Diretoria de pesquisa - DEP - Coordenação de População e Indicadores Sociais - COPIS. Estimativas da População Residente no Brasil e Unidades da Federação com Data de Referência em $1^{\circ}$ de Julho de 2018. Rio de Janeiro: IBGE, 2018a.

, em parceria com os Órgãos Estaduais de Estatística, Secretarias Estaduais de Governo e Superintendência da Zona Franca de Manaus - SUFRAMA. Produto Interno Bruto dos Municípios. 2015.

Instituto de Pesquisa Econômica Aplicada (IPEA). Caracterização e Quadros de Análise Comparativa da Governança Metropolitana no Brasil: Arranjos Institucionais de Gestão Metropolitana (Região Metropolitana de São Paulo). 2013.

MARICATO, Ermínia. As Ideias Fora do Lugar e o Lugar Fora das Ideias. In: ARANTES, Otília (et al.). A Cidade do Pensamento Único: Desmanchando Consensos. Petrópolis, RJ: Vozes, 2000.

. É a Questão Urbana, Estúpido!. In: MARICATO, Ermínia (et al.). Cidades Rebeldes: Passe Livre e as manifestações que tomaram as ruas do Brasil. São Paulo: Boitempo Editorial, Carta Maior, 2013

Metrópole na Periferia do Capitalismo: ilegalidade, desigualdade e violência. São Paulo: Hucitec, 1996.

Ninguém Conhece a Cidade Ilegal. Entrevista concedida a Carolina Stanisci. In: Revista MPD Dialógico, Ano IV, no 15, p. 8-13. São Paulo, 2007.

Para Entender a Crise Urbana. São Paulo: Editora Expressão Popular, 2015.

OLIVEIRA, Francisco de. O Estado e o Urbano no Brasil. In: Revista Espaço e Debates, v. 6, p. 36-54, 1982. 
OXFAM Brasil. A Distância Que Nos Une: Um Retrato das Desigualdades Brasileiras. 2017.

PASTERNAK, Suzana. Loteamentos Irregulares no Município de São Paulo: Uma Avaliação Espacial Urbanística. In: Planejamento e Políticas Públicas, n. 34, p. 131-170. IPEA, 2010.

PIGNATARI, Décio. Semiótica da Arte e da Arquitetura. Cotia, SP: Ateliê Editorial, 2004.

PREFEITURA DE SÃO PAULO. Plano Diretor Estratégico do Município de São Paulo: Lei 16.050, de 31 de julho de 2014 - Estratégias Ilustradas. Secretaria Municipal de Desenvolvimento Urbano, 2015. Disponível em: <https://gestaourbana.prefeitura.sp.gov.br/wp-content/uploads/2015/01/ Plano-Diretor-Estrat\%C3\%A9gico-Lei-n\%C2\%BA-16.050-de-31-de-julho-de-2014Estrat\%C3\%A9gias-ilustradas.pdf>. Acessado em 04 de maio de 2019.

REDE NOSSA SÃO PAULO. Mapa da Desigualdade 2017. 2017. Disponível em: <https:// nossasaopaulo.org.br/portal/mapa_2017_completo.pdf>. Acessado em 04 de maio de 2019.

ROLNIK, Raquel. A Cidade e a Lei - Legislação, política urbana e territórios na cidade de São Paulo. São Paulo: Studio Nobel, FAPESP, 1997.

Guerra dos Lugares: a colonização da terra e da moradia na era das finanças. São Paulo: Boitempo Editorial, 2015.

Territórios em Conflito - São Paulo: espaço, história e política. São Paulo: Três Estrelas, 2017.

SÃO PAULO (Município). Decreto 55.638, de 30 de outubro de 2014. Confere nova regulamentação à aplicação dos instrumentos indutores da função social da propriedade urbana no Município de São Paulo, em especial à notificação para o parcelamento, edificação e utilização compulsórios; revoga o Decreto nº 51.920, de 11 de novembro de 2010. Disponível em: <https:// gestaourbana.prefeitura.sp.gov.br/decreto-no-55-638-de-30-de-outubro-de-2014/>. Acesso em abril 2019.

. Lei no 13.430, de 13 de setembro de 2002. Plano Diretor Estratégico. Disponível em: <https://www.prefeitura.sp.gov.br/cidade/secretarias/upload/infraestrutura/sp_obras/ arquivos/plano_diretor_estrategico.pdf>. Acessado em 04 de maio de 2019.

. Lei 16.050, de 31 de Julho de 2014. Aprova a Política de Desenvolvimento Urbano e o Plano Diretor Estratégico do Município de São Paulo e revoga a Lei no 13.430/2002. Disponível em: $<$ https://gestaourbana.prefeitura.sp.gov.br/arquivos/PDE-Suplemento-DOC/PDE_SUPLEMENTODOC.pdf>. Acessado em 04 de maio de 2019.

SCHWARZ, Roberto. Um Mestre na Periferia do Capitalismo: Machado de Assis. São Paulo: Duas Cidades; Ed. 34, 2000.

VAINER, Carlos. Os liberais também fazem planejamento urbano? Glosas ao "Plano Estratégico da Cidade do Rio de Janeiro". In: ARANTES, Otília (et al.). A Cidade do Pensamento Único: Desmanchando Consensos. Petrópolis, RJ: Vozes, 2000.

VILLAÇA, Flavio. As Ilusões do Plano Diretor. São Paulo: Edição do Autor, 2005. Disponível em: <http://www.planosdiretores.com.br/downloads/ilusaopd.pdf>. Acessado em 04 de maio de 2019 . São Paulo, Segregação Urbana e Desigualdade. In: Estudos Avançados, v. 25, n. 71, p. 37-58, 2011. 


\section{NOTAS}

1. O presente trabalho é uma versão resumida e adaptada de alguns dos pontos trabalhados na monografia "Cidade, Direito e Política: Impactos Efetivos do Plano Diretor Estratégico do Município de São Paulo", orientada pelo Prof. Dr. Agnaldo de Sousa Barbosa e apresentada à UNESP/Franca como Trabalho de Conclusão de Curso de graduação em Direito, bem como de avanços no tema desenvolvidos durante o mestrado em Planejamento e Análise de Políticas Públicas.

2. "A história desses territórios é marcada pela estigmatização: se no mundo escravocrata devirnegro era sinônimo de sub-humanidade e barbárie, na República do trabalho livre virou marca de marginalidade. O estigma se formulou a partir de um discurso etnocêntrico e uma prática repressiva: do olhar vigilante do senhor na senzala ao pânico do sanitarista em visita ao cortiço; do registro esquadrinhador do planejador urbano à violência das viaturas policiais nas vilas e favelas" (ROLNIK, 2017, p. 206)

3. A maior parte desse valor é referente ao setor de Serviços, em ascendência, com $72,7 \%$ de participação. Por sua vez, o setor da Indústria vem reduzindo sua participação, compondo apenas 9,8\% do PIB do município. Apesar disso, o município de São Paulo continua sendo o maior polo industrial do país, com participação percentual de 5,5\% (IBGE, 2015).

4. A Bolsa de Valores de São Paulo (BM\&F BOVESPA S.A.), cuja origem remonta a 1890, é uma das maiores e principais bolsas do mundo, dando papel de destaque para São Paulo também no âmbito do mercado financeiro.

5. O Estado de São Paulo: "1\% dos donos de imóveis concentra $45 \%$ do valor imobiliário de São Paulo". 13/08/2016. Disponível em: http://www.estadao.com.br/noticias/geral,1-dos-donos-deimoveis-concentra-45-do-valor-imobiliario-de-sao-paulo,10000069287. Acessado em 04 de maio de 2019.

6. "Assim, a vida brasileira impunha à consciência burguesa uma série de acrobacias que escandalizam e irritam o senso crítico. [...] Nestas circunstâncias, [...] além de infração, a infração é norma, e a norma, além de norma, é infração, exatamente como na prosa machadiana. [...] os setores europeizantes da sociedade brasileira participavam sim da civilização burguesa, embora de modo peculiar, semidistanciado, que levava a invocá-la e descumpri-la alternada e indefinidamente. (SCHWARZ, 2000, p. 29-30)

7. A coluna da economista Laura Carvalho do dia 03/05/2018 ("Ocupações de risco mostram drama do acesso à moradia nas metrópoles"), no jornal Folha de São Paulo, deixa claro esse avanço: "O índice Fipe-Zap mostra que, entre janeiro de 2008 e março de 2018, os preços de venda dos imóveis em São Paulo subiram 257,3\%. No mesmo período, o Ibovespa avançou 43,5\%, os preços medidos pelo IPCA subiram $80,3 \%$ e o rendimento nominal médio dos trabalhadores empregados na região metropolitana de São Paulo cresceu 140\%." Disponível em: https:// www1.folha.uol.com.br/colunas/laura-carvalho/2018/05/ocupacoes-de-risco-mostram-dramado-acesso-a-moradia-nas-metropoles.shtml. Acessado em 04 de maio de 2019.

8. David Harvey (2015) mostra como esse processo de valorização de territórios específicos, com infraestrutura e serviços de qualidade, em detrimento do restante da cidade, é algo que tem acontecido em todo o mundo. Desse modo, como demonstra o autor, o que tem ocorrido é que em todo o mundo o direito à cidade tem se tornado um direito limitado apenas às classes dominantes.

9. A lei 10.257 , de 10 de julho de 2001, conhecida como Estatuto da Cidade, traz a gestão democrática como uma de suas diretrizes (art. $2^{\circ}$, II) e dedica um capítulo específico a regulamentar esse tema (Capítulo IV - Da Gestão Democrática da Cidade), o qual vai do art. 43 ao art. 45.

10. No Plano Diretor de São Paulo, a ideia de uma gestão participativa e democrática do espaço urbano está integrada aos princípios da lei (art. $5^{\circ}$ VII e art. $5^{\circ}$, $\$ 7^{\circ}$ ), e é melhor desenvolvida no 
Título IV (Da Gestão Democrática e do Sistema Municipal de Planejamento Urbano), que abarca do art. 318 ao art. 359.

11. As únicas exceções no território do Município ao Coeficiente Básico igual a 1 são as Macroáreas de Recuperação Urbana e Ambiental, Contenção Urbana e Uso Sustentável, e Preservação de Ecossistemas Naturais, onde esse coeficiente é menor (0,2 para as duas primeiras e 0,1 para a última), por se tratar de regiões onde o Poder Público pretende desestimular a ocupação.

12. Os instrumentos indutores da função social da propriedade são regulamentados pelo Decreto nº 55.638 de 2014.

13. Cabe destacar rapidamente que o PDE-SP também pretende enfrentar diretamente a questão da concentração de empregos em apenas uma localidade da cidade. Para isso, cria áreas estratégicas que têm por objetivo ampliar a oferta de emprego de forma descentralizada, tornando mais homogênea a distribuição dos postos de trabalho. Entram nessa questão os Polos Estratégicos de Desenvolvimento Econômico, os Perímetros de Incentivo ao Desenvolvimento Econômico, os Polos de Economia Criativa, o Polo de Desenvolvimento Rural, entre outros.

14. Utilizamos, aqui, ideia defendida por Christian Dunker em conferência sobre o Direito à Cidade realizada na Biblioteca Mário de Andrade, como parte do ciclo de debates sobre a Democracia na História. Para tal leitura da questão, o autor baseia-se, entre outros, na obra "O Mal-Estar na Civilização", de Freud. A íntegra da conferência está disponível em: https:// www.youtube.com/watch?v=ejinqlFIP7M. Acessado em 04 de maio de 2019.

15. No presente caso, esse fato é bem exemplificado pelas medidas essencialmente inversas àquilo que preconiza o PDE-SP tomadas pela gestão Dória-Covas à frente da Prefeitura de São Paulo

\section{RESUMOS}

O presente trabalho pretende evidenciar o quadro atual de desigualdades socioespaciais existentes na cidade de São Paulo, demonstrando, a partir de dados e análise bibliográfica, como esse espaço urbano é marcado por enormes discrepâncias que são reflexo material das características econômicas, políticas e sociais do Brasil. No entanto, entendendo que essa situação engendra reações que vão no sentido de transformar a conjuntura exposta, em um segundo momento o trabalho analisa os instrumentos jurídico-urbanísticos trazidos pelo Plano Diretor Estratégico do Município de São Paulo (Lei $n^{\circ}$ 16.050/14) que se propõem a enfrentar tal quadro de desigualdades socioespaciais na cidade. Por fim, apresenta um balanço sobre os avanços e as limitações da referida legislação para a transformação dessa realidade.

Cet article a pour but de mettre en lumière le tableau actuel des inégalités socio-spatiales dans la ville de São Paulo, en démontrant, à partir de données et d'analyses bibliographiques, en quoi cet espace urbain est caractérisé par d'énormes différences reflétant de manière substantielle les caractéristiques économiques, politiques et sociales du Brésil. Cependant, comprenant que cette situation engendre des réactions visant à transformer la conjoncture exposée, le travail analyse ensuite les instruments urbanistiques et légaux apportés par le Plan Directeur Stratégique de la Municipalité de São Paulo qui proposent de faire face à cette scénario d'inégalités socio-spatiales dans la ville. Enfin, il présente un équilibre entre les avancées et les limites de la législation susmentionnée pour transformer cette réalité. 
El presente trabajo pretende evidenciar el cuadro actual de desigualdades socioespaciales existentes en la ciudad de São Paulo, demostrando, a partir de dados y análisis bibliográfico, cómo ese espacio urbano es marcado por enormes discrepancias que son reflejo material de las características económicas, políticas y sociales de Brasil. Sin embargo, entendiendo que esa situación engendra reacciones que van en el sentido de transformar la coyuntura expuesta, en un segundo momento el trabajo analiza los instrumentos jurídico-urbanísticos traídos por el Plan Director Estratégico del Municipio de São Paulo (Ley $n^{\circ}$ 16.050/14) que se proponen enfrentar este cuadro de desigualdades socioespaciales en la ciudad. Por último, presenta un balance sobre los avances y las limitaciones de dicha legislación para la transformación de esta realidad.

This paper aims to show the current situation of social and spatial inequalities in the city of São Paulo, demonstrating, from data and bibliographical analysis, how this urban space is marked by enormous discrepancies that are the material reflection of economic, political and social characteristics of Brazil. However, considering that this situation engenders reactions that intend to transform the exposed situation, in a second moment the paper analyzes the urban legal instruments brought by the Master Plan of São Paulo that are proposed to face such a framework of socio-spacial inequalities in the city. Finally, it presents an assessment of the progress and limitations of the legislation for the transformation of this reality.

\section{ÍNDICE}

Mots-clés: Droit à la Ville; Sociologie Urbaine; Droit Urbain; Production de L'espace; São Paulo Keywords: Right to the City; Urban Sociology; Urban Law; Production of the Space; São Paulo. Palabras claves: Derecho a la Ciudad; Sociología Urbana; Derecho Urbanístico; Producción del Espacio; São Paulo.

Palavras-chave: Direito à Cidade; Sociologia Urbana; Direito Urbanístico; Produção do Espaço; São Paulo.

\section{AUTOR}

\section{JACQUES FELIPE IATCHUK VIEIRA}

Mestrando em Planejamento e Análise de Políticas Públicas, Bacharel em Direito, ambos pela Faculdade de Ciências Humanas e Sociais da Universidade Estadual Paulista "Júlio de Mesquita Filho" (FCHS - UNESP/Franca). E-mail: jf.iatchuk@gmail.com. 